\title{
The Social Action of Healthcare Workers to Educate Mental Health Literacy for Family of Patient with Mental Disorders in Kalawa Atei Mental Hospital
}

\author{
Suyuti Syamsul $^{{ }^{*} \text {, Ishomuddin }}{ }^{2}$, Rinikso Kartono ${ }^{3}$, Tri Sulistyaningsih ${ }^{4}$ \\ ${ }^{1}$ Doctor Candidate of Social and Political Sciences of University of Muhammadiyah Malang \\ ${ }^{2}$ Professor of Sociology of Islamic Society of University of Muhammadiyah Malang, \\ ${ }^{3}$ Doctor of Social Welfare of University of Muhammadiyah Malang \\ ${ }^{4}$ Doctor of Sociology of University of Muhammadiyah Malang
}

\author{
*Corresponding Author: Suyuti Syamsul, Doctor Candidate of Social and Political Sciences of \\ University of Muhammadiyah Malang
}

\begin{abstract}
Although people with severe mental disorders are quite large in Indonesia, but public mental health literacy isn't good enough. KalawaAteiMental Hospital attempts to enhance mental health literacy of patients' families through education, butresults aren't as expected. Mental health literacy isn't implemented by patients' families for various reasons. The social actions of healthcare workersto educate patient's family need to be focusedin order to enhance mental health literacy. Healthcareworkers have freedom to choosemethods, tools, techniques and goals. The objectives of this studyare as follows: to describemental health literacy problems of patient's family, to describe goals of healthcare workers, to understand rationality of social actions of healthcare workers, to understand the selection of methods, tools and techniques. This study was conductedused a qualitative approach and phenomenologystudy. Data were collected through interviews, observations and documentations. This study wasconducted at both intensive careand inpatient facilities.Subjectsof study werepurposefully selected. Data were analyzed using Creswell's techniques as follows managing, reading and memoing, describing, classifying, interpreting, representing and visualizing.
\end{abstract}

Key words: Social Action, Healthcare Workers, Literacy, Mental Health, Patient's Family

\section{INTRODUCTION}

The prevalence of severe mental illness in Indonesia is $1.7 \%$. Households put their family members in shackles $14.3 \%$ (Balitbangkes, 2013). In fact, number of people with severe mental disorder in Indonesia are continuously increasing, but public mental health literacy isn't good enough. The main problems of mental health in Indonesia is low level of mental health literacy (Surjaningrum, 2012) whereas mental health literacy has an important role to seek help (Novianty\&Hadjam, 2017). The government of Indonesia struggles to enhance public mental health literacy through shackle free campaigns (Kemenkes, 2017). However, all patients' families have been educated by healthcare workers in Kalawa Atei Mental Hospital, but results haven't yet as expected. Patients who have recovered and returned to their families end up in shackles or released living on the streets. A few patients who recovered were not picked up by their families. Patients aren't accompanied by their families for regular medical treatment in KalawaAtei Mental Hospital. Hence, patients' families return to seek helps from belians (shaman) or traditional healers.

Healthcare workers have freedom to choose methods, tools, techniques as well as determine goals to be achieved. The actions of healthcareworkersneed to be studied in order to find outitsrationality. Rationality of healthcare workers' social actions depends on: (1) the selection of methods, tools and techniques consider the situation and condition of the patient's family; (2) use different approach according to the needs of the patient's family, and; (3) solely for the benefit of the patient's family. Due to the studies on social actions of health workers are rarely, researcher is interested to do this study. The objectives of this study are to describe mental health literacy problems of patient's family, to describe goals of healthcare workers, to understand rationality of social actions of healthcare workers, and to understand the selection of methods, tools and techniques. 


\section{LITERATURE REVIEW}

\subsection{Mental Health Literacy and Family Support}

Mental health literacy refers to knowledge and belief about mental disorders that can help someone to identify, to manage and to prevent mental disorder. Mental health literacy includes the ability to recognize specific disorders or different types of psychological distress; knowledge and beliefs regarding risk factors and causes of mental illness; knowledge and understanding of self-help; knowledge and belief about the availability of healthcare workers' assistances; attitudes toward seek for appropriate helps, and; knowledge of how to find information about mental health (Jorm, 2000).

Patients' families have very important roles to treat patients because patients' families can be a cause of mental disorders. Patients' families are responsible to care and to contribute in process of treatment. Recognition of the important role of patients' families in the treatment of mental disorders has only recently emerged (Kumar \& Tiwari, 2008). Cooperation between patients' families and healthcare workers is very helpful to increase understanding of experiences, and roles of family in rehabilitation process (Spaniol, Zlpple\& Lockwood, 1992).

\subsection{Action Theory}

Social action uses means ends framework model (Parsons, 1949). The social actions havegoalsand always are directed to achieve the goals. The actorsselectmethods, tools techniques and procedures which are the most efficient and the most appropriate to achieve the goals. Actors are restricted by certain conditions that all can't be solved and become a limit of continuity of action. Actors make decisions always considering norms, rules and moral principles (Ritzer, 2014). Actor has ability to choose which is called by Parsons as voluntarism. Actors decide to act by selecting tools and methods which are the most effective and the most efficient to achieve actors' goals (Ritzer, 2014; Ritzer, 2005). Based on pattern variables of Parson, actions of healthcare workers to educate patient's family can be categorized as affective neutrality, collective orientation, universalism, performance and diffuse (Poloma, 2010).

\subsection{Social Action Theory}

According to Weber (Ritzer, 2014), social action is an individual action that has subjective meanings for actor. Social action can be a manifestly action an act of thinking aimed at others. Social action is a subjective action that occurs because of the positive influence of certain situations. According to Ritzer (2005), social action is a process by which an actor attaches subjective meaning. The goal of actors in a social action is to seek consensus based on rational argument (Ritzer \& Smart, 2003). Weber divides social action into four types based on his rationality, namely instrumentally rational action, value rational action, affectual action and traditional action (Ritzer, 2014; Ritzer, 2005; Kalberg, 1980). In daily life, many social actions involve combinations of four types of social action (Ritzer, 2005). Social actions of healthcare workers to educate patient's family based on rationality are instrumentally rational.

\section{METHODOLOGY}

\subsection{Research Approach}

This study uses a qualitative approach and study of phenomenology. Qualitative study has a wide variety, relying on data in the form of text and images (Creswell, 2016; Fraenkel, Wallen \& Hyun, 2012).Findings on qualitative study aren't obtained through statistical procedures (Strauss \& Corbin, 2015). Researcher isa key instrument directly involved in collecting data. Qualitative approach appropriates for this study because research process will dynamicallydevelop. Phenomenology was chosen because it can be used to find out the subject's conscious experiences, goals, and intentions of a social action. Phenomenology enable researcher to describe the meaning of social actions and to explore the structure of healthcare workers consciousness. Phenomenology allows researcher to know the types of social actions of healthcare workers. According to Denzim\& Lincoln (2009), phenomenology departs from subjective assumptions about the true nature of an individual's experience and social order.

\subsection{Research location and Research Subjects}

The study was conducted both at intensive care facilities and inpatient facilities of KalawaAteiMental Hospital. There were eight healthcare workers selected as the subject of this research. Subjects were purposefully selected based on criterion and maximum variation. 


\subsection{Data Analysis}

Data analysis was performed at every stage of this study until the data were complete and saturated. Data analyzed using technique which is recommended by Creswell (2007) as follows: managing, reading and memoing, describing, classifying, interpreting, representing and visualizing.

\section{RESUlT AND DISCUSSION}

\subsection{Result}

\subsubsection{Problem of Mental Health Literacy of Patient's Family}

Mental health literacy of patients' families isn't good enough and is influenced by education, economy and culture. KalawaAteiMental Hospital attempts to enhance mental health literacy of patients' families through education. Healthcare workers are required to educate patient's family. Patient's families didn't understand that their family members are suffer from mental disorder. They know after healthcare workers notify them. Families of patients decide to go to KalawaAteiMental Hospital for seeking helps influenced by extended families, campuses, belians, traditional healers and healthcare workers at primary health care. They encourage patients' families to go to KalawaAtei Mental Hospital for seeking second opinions.

Family member wascarriedtoseek treatments at KalawaAteiMental Hospital after annoying community. Mental disorders relapse because patients don't go back to KalawaAtei Mental Hospital for regularly control. Patients' families consider mental disorders to be caused by non-medical factors such as witchcraft, curse and spirits. Belians or traditional healers to be the first place for patients' family to seek helps. Belians or traditional healers give water on the bottle to patient's families. The water was given prayer or spells by belians or traditional healers and then patients' families give the water as medication to patient. Some patients' families admit patients to pesantren, an Islamic traditional boarding school, for seek helps.

\subsubsection{Goals to be Achieved by Healthcare Workers}

Director of KalawaAteiMental Hospital determinesgoalsto educate patients' families. One of the goals is to enhance the cooperation of patients' family during the process of treatments. Families of patients are expected to change parenting and perspective, to understand patient's condition, to accompany patient to control regularly, to supervise taking medication, to recognize early signs of mental disorders recurrence, to seek help at health facilities, to know side effects of medication, and to provide activities for patients. Healthcare workers expect the cooperation of patient's family, during hospitalization at KalawaAteiMental Hospital as well as after returning to their home. Cooperation of patient's families is a very important factors for healing process and preventing recurrence of mental disorders. Healthcare workers expect that education will increase mental health literacy not only for patients' families but also for community.

\subsubsection{Rationality of Social Action of Healthcare Workers}

Educating patient's family is governed by guideline and standard operating procedure (SOP) which are established by Director of the KalawaAteiMental Hospital. Guideline and SOP as values and norms must be followed by healthcare workers. Healthcare workers are required to attend effective communication training before giving education and will be periodically evaluated. Healthcare workers must educate patients' families in order to increase their mental health literacy. Unfortunately, most patients' families don't implement mental health literacy that has been given such as (1) patient's families didn't accompany patient to control regularly; (2) patients were put back on shackle; (3) patients' families returned to seek helps at belians or traditional healers; (4) refused to accept patients, and; (4) mental disorders relapse. Patient's family didn't implement mental health literacy because of culture, social, economic, belief, distance, no incentive, lack of knowledge, working for living and considering patients permanently recovery.

Healthcare workers try to solve any obstacles of patients' families by giving out his personal phone number, calling patients' families, giving consultations outside KalawaAteiMental Hospital, and promising incentives. Patients' families are requested to keep phone number of KalawaAteiMental Hospital so that they can consult any time. Patient's families are encouraged to implement mental health literacy by involving religious leaders, community leaders and tribal leaders. The leaders involve when patient's family request them, home visits or accompany patient. 
Obstacles of healthcare workers to educate patients' families are language, belief in non-medical factors and lack of knowledge. Language barriers are solved by asking translators or other staff at KalawaAteiMental Hospital for help. Giving education will be postponed by healthcare workers if there is no translator or other staffs available at the time. If there is no one understand the language at KalawaAtei Mental Hospital, healthcare workers ask language institution for help. Because of no cooperation agreement between language institute and KalawaAteiMental Hospital, healthcare workers solve the problem by asking staff of language institute for personal assistance. Some healthcare workers use local languages when give education to make easer for patients' families. Belief in non-medical factors is overcome by allowing patient to drink water from belians or traditional healers, but doctor's medication must be taken regularly. Lack of knowledge is overcome by inviting other family members to take part in education.

Healthcare workers don't always follow guideline and SOP. They adjust according to the situation and condition of the patient's family, while still paying attention to basic principles. Healthcare workers not only adjust but also violate the guideline and SOP. In order to achieve the goals, healthcare workers violated the guidelines and SOP by giving personal phone numbers to patients' families, giving consultations outside KalawaAteiMental Hospital, asking patient's family to come out when giving education, asking staff of language institute for personal assistance, and allowing to drink water from belians or traditional healers.

\subsubsection{Selection of Methods, Tools and Techniques}

Healthcare workers select methods, tools and techniques base on situation and condition of patient's family. Healthcare workers use interviews, leaflets, blank paper and flipcharts to educate patients' families. Leaflets, flip sheets and blank papers are always combined with interviews. Patient's use blank paper to scribble. Healthcare workers invite patient's families to read leaflet together until they understand.

\subsection{Discussion}

Findings of this study are in accordance with theory of action and theory of social action with several differences. Guidelines and SOP are values and norms that bind and limit health care workers when giving education to the patient's family. As creative actors, healthcare workers do not always follow the guidelines and SOP. Healthcare workers have ability and freedom to adjust to the situation and condition of patient's family. According to Ritzer (2014), actors in acting are not entirely determined by norms and values.

The action of health workers in giving education is in accordance with Parsons' theory of action. According to Parsons (1949), social action uses means ends framework model. Social actions always have a goal and always directed to achieve goals. Giving education intend to encourage patient's family to cooperate with healthcare workers to treat patient. Healthcare workers in selecting methods, tools and techniques always consider values and norms. Healthcare workers adjust due to situation and condition of the patients' family but still follow the basic principles of guideline and SOP. According to Parson (1949), social actions occur in certain situation and have basic elements i.e. goals, tools, conditions, values and norms. Basic elements are used by actors as a tool to achieve the goals. Actorsarrangetheiractionsaccordingtothetoolsandgoals.

According to Parsons (Ritzer, 2014), there are five basic units of social actions. Compare to the finding of this study, three of five are appropriate and two of five are different. Three basic units are fully compliant i.e. (1) the presence of individual healthcare workers as actors; (2) actors as a goal hunter, and (3) actors have methods, tools and techniques to achieve goals. Two basic units are different i.e. (1) action of actors are limited by a number of situational conditions that can't be controlled and (2) actors are under control by values, norms and other abstract ideas that influence actors in choosing and determining the goals as well as alternative actions to achieve it.

Healthcare workers are restricted by several conditions such as language, knowledge and belief to achieve their goals, but all of them can be overcome. Healthcare workers deal with these condition by giving personal phone number, contacting patient's family by phone, giving consultations outside KalawaAteiMental Hospitals, promising incentives, asking interpreters or other staff for assistance, postpone to give education; asking staff of language institute for personal assistance, allowing patients to drink water from belians or traditional healers, and allowing other family members to take part in education. 
Health workers are regulated and controlled by guideline and SOP, but healthcare workers don't rigidly follow it. Healthcare workers consciously violate guideline and SOP by giving personal phone numbers, contacting patient's family by phone, giving consultations outside KalawaAteiMental Hospitals, asking staffs of language institute for personal assistance, and allowing patients to drink water from beliansor traditional healers. Accordance to Parson's concept of pattern variables, the action of healthcare workers in giving education is a neutral, group oriented, universal, merit and blend.

Giving education to enhance mental health literacy has a subjective meaning for healthcare workers. This is also a real action addressed to the patient's family. According to Weber (Ritzer, 2014a), social action is an individual action that has subjective meanings to actors and is addressed to others. Social actions can be in the form of actions that are clearly directed to other people or actions that are thinking. The social actions occur because of positive influence of certain situations.

The actions of healthcare workers in giving education are directed action for the present time and for the future. The action being directed at the present time aims to get patient's family cooperation during patient being treated in KalawaAtei Mental Hospital. Actions directed at the future aim to ensure that the patient's family implements mental health literacy after the patient is returned to his home. Healthcare workers give education not only to obtain patient's family cooperation, but also to enhance mental health literacy of community. According to Ritzer (2014), social actions based on the time of occurrence can be divided into actions directed at the present, past or future. According to the target, social action can be aimed at a person or group.

Before giving education, healthcare workers assess the situation and condition of patient's family. Healthcare workers consider choosing methods, tools and techniques based on the ability, situation and condition of the patient's family. Obstacles are overcome by healthcare workers in various ways. Selection of methods, tools and techniques is done by healthcare workers in order to get responds of patient's family as expected. The social actions of healthcare workers in giving education are instrumentally rational. According to Ritzer (2005), instrumentally rational action is a pure rational action performed by actors after careful consideration. Actors consider the goals and the ways that will be taken to achieve the goals. Rationality of instrumentally rational action refers to expectation to get other actors' responses.

Giving education to the patient's family has two goals. Firstly, patients' families cooperate during patient being treated. Secondly, patients' families implement mental health literacy after patients being returned to his home. According to Ritzer (2014), actors not only assess methods to achieve goals but also determine the value of goals. Actor's goal in instrumentally rational action isn't an absolute goal because it can be used by actor to achieve the next goal.

The first goal which is an intermediate goal, is relevant to the decision of healthcare workers. The second goal, which is a final goal, is irrelevant to the decisions of healthcare workers. Patient's families intentionally didn't implement mental health literacy for various reasons. This is different to Ritzer (2014), actors consciously make decisions among various alternatives that are available based on consideration to the final goal. Actors expect result relevant to actor's decisions. The healthcare workers and patients' families reach consensus on the first goal. The Patients' families are willing to cooperate with healthcare workers by agreeing their family members to be treated in KalawaAteiMental Hospital. The healthcare workers and patients' families didn't reached consensus on the second goal. Healthcare workers didn't communicate directly to the patient's family so that patient's family doesn't implement mental health literacy intentionally for various reasons. This is different to Ritzer \& Smart (2003), actors'goalsina social action are to reach consensus based on rational argumentation.

\section{CONCLUSION}

Mental health literacy of patients' families isn't good enough and is influenced by education, economy and culture. Healthcare workers give education in order to enhance mental health literacy of the patients' families. Families of patient decide to go to KalawaAtei Mental Hospital for seeking help influenced by other people. Good mental health literacy encourages patients' families to cooperate with healthcare workers. Healthcare workers expand the goals of giving education to enhance mental health literacy of community. 
The actions of healthcare workers to educate patients' families are neutral, group-oriented, universal, merit and diffuse. Healthcare workers are regulated and controlled by guidelines and SOP, but they don't always follow it. Healthcare workers make adjustment based on consideration to the situations and conditions of patients' family. Three of the five basic units of social action are appropriate and the other two basic units differ to the research findings. Obstacles found by health workers when giving education can be coped even though health workers must violate guideline and SOP.

The action of healthcare workers in giving education has a subjective meaning and is clearly aimed to the patient's family. Actions are directed for the present and for the future. Healthcare workers assess the situation and condition of patient's family. The social action of health workers is an instrumentally rational. Rationality of the social action of healthcare workers refers to expectation of getting patient's family responses.

\section{REFERENCES}

[1] Badan Penelitian dan Pengembangan Kesehatan Kementerian Kesehatan RI (Balitbangkes). Risetkesehatandasar. Jakarta, Indonesia: Kementerian Kesehatan, 2013.

[2] Surjaningrum, E.R. Gambaran mental health literacy kaderkesehatan. Jurnal Insan Media Psykologi Fakultas Psikologi, Vol. 14 (3), pp 94-202, 2012

[3] Novianty, A. dan Hadjam, M.N.R. Literasikesehatan mental dan sikap komunitas sebagai prediktor pencarian pertolongan formal. Jurnal Psikologi, 44(1), pp 50 - 65. DOI: 10.22146/jpsi.22988, 2017.

[4] Kementerian Kesehatan Republik Indonesia(Kemenkes). Peraturan Menteri Kesehatan Nomor 54 tahun 2017 tentang penanggulangan pemasungan orang dengan gangguan jiwa. Jakarta, Indonesia: Kementerian Kesehatan, 2017.

[5] Jorm, A.F. Health literacy: Public knowledge and beliefs about mental health disorder, The British Journal of Psychiatry, Vol. 177, pp 396-401, 2000.

[6] Kumar, P., \& Tiwari, S.C. Family and psychopathology: an overview. Delhi Psychiatry Journal, Vol. 11 (2), pp 140-149, 2008.

[7] Spaniol, L., Zlpple, A.M., \& Lockwood, D. The role of the family in Mental rehabilitation. Schizophrenia Bulletin, Vol. 18(3), pp 341- 348, 1992.

[8] Parsons, T. The structure of social action, a study in social theory. Illinois, USA: The Free Press Glencoe. 1949.

[9] Ritzer, G. Sosiologi ilmu pengetahuan berparadigma ganda. Jakarta, Indonesia: Raja Grafindo Persada, 2014.

[10] Ritzer, G. (ed.).Encyclopedia of social theory (Vol. 2). London, England: Sage Publication, 2005.

[11] Poloma, M.M. Sosiologikontemporer. Jakarta, Indonesia: P.T Raja Grafindo Persada, 2010.

[12] Ritzer, G., \& Smart, B. (eds.). Handbook of social theory. London, England: Sage Publication. 2003.

[13] Kalberg, S. Max Weber's types of rationality: Cornerstones for the analysis of rationalization processes in history. The American Journal of Sociology, Vol. 85(5),pp 1145-1179. doi: 10.1086/227129. 1980.

[14] Creswell, J.W. Research design: pendekatanmetodequalitatif, kuantitatif dan campuran. (4 ${ }^{\text {th }}$ ed.). Yogyakarta, Indonesia: Pustaka Pelajar, 2016.

[15] Fraenkel, J.R., Wallen, N.E. and Hyun, H.H. How to design and evaluate research in education. ( ${ }^{\text {th }}$ ed.). New York, USA: McGraw-Hill, 2012.

[16] Strauss, A. dan Corbin, J. Dasar-dasarpenelitiankualitatif, tatalangkah dan teknik-teknikteoritisasi data. Yogyakarta, Indonesia: Pustaka Pelajar, 2015.

[17] Denzim, D.K. \& Lincoln, Y.S. (eds.).Handbook of qualitative research. Yogyakarta, Indonesia: Pustaka Pelajar, 2009.

[18] Creswell, J.W. (2007). Qualitative inquiry and research design choosing among five approaches. ( ${ }^{\text {nd }}$ ed.). Thousand Oaks, USA: Sage Publications.

\section{AUTHORS' BIOGRAPHY}

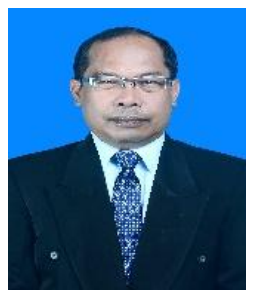

Suyuti Syamsul, is aDoctor Candidate of Social and Political Sciences of University of Muhammadiyah Malang. He also is a medical doctor who was a director of several hospital. 
The Social Action of Healthcare Workers to Educate Mental Health Literacy for Family of Patient with Mental Disorders in Kalawa Atei Mental Hospital

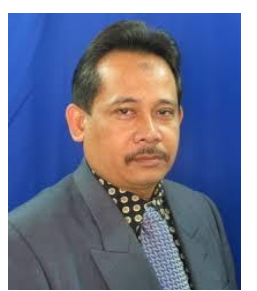

Ishomuddin, is a Professor of Sociology of Islamic Society of University of Muhammadiyah Malang. His diligence in writing and spreading his knowledge was proven by publishing his writings in various national and international journals.

Citation: Suyuti Syamsul, et.al. "The Social Action of Healthcare Workers to Educate Mental Health Literacy for Family of Patient with Mental Disorders in Kalawa Atei Mental Hospital" International Journal of Humanities Social Sciences and Education (IJHSSE), vol 7, no. 5, 2020, pp. 45-51. doi: http://dx.doi.org/10.20431/2349-0381.0705006.

Copyright: (c) 2020 Authors. This is an open-access article distributed under the terms of the Creative Commons Attribution License, which permits unrestricted use, distribution, and reproduction in any medium, provided the original author and source are credited. 